\title{
The Identification of Randles Impedance Model Parameters of a PEM Fuel Cell by the Least Square Method
}

\author{
$\mathrm{M}^{\mathrm{ed}}$ Selméne Ben Yahia \\ Laboratory of Energy Efficiency \\ Application and Renewable Energy \\ LAPER, Tunis El Manar University, \\ Faculty of Sciences, Tunisia
}

\author{
Hatem Allagui \\ Laboratory of Energy Efficiency \\ Application and Renewable Energy \\ LAPER, Tunis El Manar University, \\ Faculty of Sciences, Tunisia
}

\author{
Abdelkader Mami \\ Laboratory of Energy Efficiency \\ Application and Renewable Energy \\ LAPER, Tunis El Manar University, \\ Faculty of Sciences, Tunisia
}

\begin{abstract}
One of the problems of industrial development of fuel cells is the reliability of their performances with time. The solution of this problem is through by the development of improved diagnostic methods such as the identification of parameters. This work focuses on the modeling and the identification of the impedance model parameters of a Proton Exchange Membrane (PEM) fuel cell. It is based on the Randles model represented by specific complex impedance at each cell. We have used the "Least square" method to determine the parameters model using measured reference values. The proposed authentication method is valid for Randles model, but it can be generalized to be applied to others.
\end{abstract}

Keywords-Randles model; impedance; Proton Exchange Membrane (PEM) fuel cell; modeling; parameters identification; least square

\section{INTRODUCTION}

The fuel cell is not a source of energy, but a converter that directly transforms the chemical energy of a fuel into electrochemically powered and its working principle was discovered in 1839 by W. Grove [1], [2]. It is an efficient means of electrical production in terms of efficiency. However, behind the displayed simplicity of its operating principle, it may indeed appear as a relatively complex to be technically implemented. The modeling of a fuel cell is an important factor in describing the operation of the fuel cell system through a well-defined model, and more precisely the fuel cell impedance model that describes the frequency behavior. The objective is not to describe in detail and exhaustively all the models present in the fuel, but rather to highlight the dynamic model in which one can easily identify its parameters.

Our choice was the impedance model. There were two reasons for this choice; the first is the validity of the impedance model of the fuel cell at the electrical level and the multiphysics phenomena. This model permits to generate the polarization curve and the Nyquist diagram as a function of the frequency from a well-defined scan. The second reason is the importance of the impedance model to facilitate the diagnosis of the fuel cell and to prolong the life of the fuel cell. The identification of impedance model parameters is necessary to model diffusion phenomena, hence the need to use optimization and identification methods. The objective of this article is to judge the methodology for identifying the impedance model parameters of the fuel cell used and to validate it by experimental results. The use of parametric identification requires to be coupled to another approach, most often using decision to accomplish the task of diagnosis [3]. Among the methods using an equivalent electrical circuit, we can cite the author's work [4] which has established a model based on a so-called current interruption measure for the estimation of parameters of the PEM fuel cell in order to diagnose its state. Other authors [5] have developed another equivalent electrical circuit consisting of three $\mathrm{RC}$ cells placed in series to model the non-linear relationship between voltage and current. This method was used to detect the phenomenon of flooding. In order to diagnose the cell, a method has been found to determine the correlation between the resistance value of the diffusion layer and the water content in the cell [6]. The parameters were studied using an extended Kalman filter, in the case of dynamic stresses in current [7]. Another method of identification based on the generalized moments of input and output from current-jump measurements allowed knowing the evolution of the electrochemical phenomena during an aging process.

The identification methods have the advantage of being simple to implement; however, the diagnostic method may present operational difficulties due to the use of test signals. This is why its implementation must be accompanied by a complementary strategy, especially during real-time applications. In [8], the authors propose the extrapolation of the laws applied to electrical circuits (law of nodes and meshes) on other hydraulic or pneumatic systems. The proposed model for the fuel cell is capable of monitoring the evolution of anode and cathode gas dynamics (pressure and flow) and predicting the fuel voltage. The model allows the detection of the deterioration of the membrane, the drying and the flooding of the cells. Diagnosis is based on the identification of resistance to flow. For example, a flooding defect is located at the cathode if the drop in the cell voltage is gradual, the resistances equivalent to the cathode increase and those of the anode remain invariant.

We will start with the presentation of the PEM fuel cell. Then, we will explain the impedance circuit and the analysis of the effect of the frequency behavior on the defined scan. In the 
third part, we will detail the procedure for identifying the parameters of the proposed model to be developed by a Matlab environment program.

\section{DESCRIPTION OF THE PEM FUEL CELL}

The principal role of the full cell is to convert the chemical energy of a fuel into electrochemically electricity. There are several cell technologies to fuel characterized by the nature of the electrolyte, the operating temperature, the gas consumed.

The five categories of fuel cell are:

- AFC (Alkaline Fuel Cell)

- PEMFC (Proton Exchange Membrane Fuel Cell)

- PAFC (Phosphoric Acid Fuel Cell)

- $\quad$ SOFC (Solid Oxide Fuel Cell)

- MCFC (Molten Carbonate Fuel Cell).

Each type contains a fuel cell, an oxidizer, an electrolyte, electrodes, an important and different temperatures for each type, the chemical reactions at the anode and cathode also are important for the functioning of the pile.

\section{A. Fuel Cell Exchange Membrane PEM Proton}

The PEMFC (Proton Exchange Membrane Fuel Cell) is a fuel cell operating at low temperature (between $30^{\circ} \mathrm{C}$ and $90^{\circ} \mathrm{C}$ ). Its basic principle is the electrochemical combustion of hydrogen and oxygen [9]. The simplest system allows from hydrogen and oxygen, supply water, electricity and heat.

Fig. 1 expresses the principle of operation of a PEM cell.

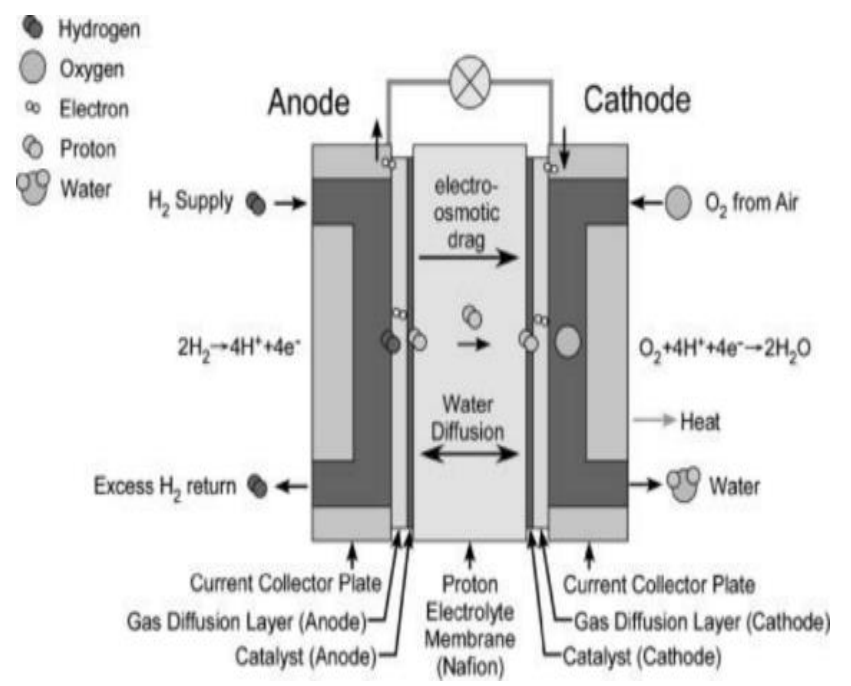

Fig. 1. The Operating principle of a PEM fuel cell.

A fuel cell consists of three main elements [10]:

- The anode which is fed by a fuel (hydrogen, methanol, etc.).

- The cathode which is fed with an oxidizer (oxygen).

- The electrolyte, solid or liquid, which separates the two electrodes and to provide the distribution of the intermediate ion of the oxidation reaction of the fuel cell.

The electrolyte must prevent the passage of electrons through the electrical circuit. The reaction produced is the reverse reaction of the electrolysis of water. The overall reaction is:

$$
2 \mathrm{H}_{2}+\mathrm{O}_{2} \rightarrow \mathrm{H}_{2} \mathrm{O}
$$

\section{B. Electrical Characteristics of PEMFC}

We recall a few laws of thermodynamics necessary to understanding the external characteristics of fuel cells. In general, the balance of a reaction is written [11]:

$$
\alpha \mathrm{A}+\beta \mathrm{B} \rightarrow \delta \mathrm{C}
$$

The gas activity is defined by: $\mathrm{a}=\mathrm{P} / \mathrm{P}^{0}$

Where, $\mathrm{P}$ and $\mathrm{P}^{0}$, respectively represent the partial pressure of gas and the standard pressure. The variation of the Nernst equation for the reaction is expressed by [12]:

$$
\mathrm{E}=\mathrm{E}_{0}+\frac{\mathrm{RT}}{\mathrm{nF}} \ln \left(\frac{\mathrm{a}_{\mathrm{A}}^{\alpha} \mathrm{a}_{\mathrm{B}}^{\beta}}{\mathrm{a}_{\mathrm{C}}^{\delta}}\right)
$$

Where, $\mathrm{R}$ is the universal constant of gas equal to 8,314 J.mole ${ }^{-1} \cdot \mathrm{k}^{-1}$.

This last equation is the general form of the Nernst equation. It shows the dependency of the load voltage with pressure at constant temperature. Thus, the theoretical voltage of a cell increases when the activity of the reactants increases and the activity of the products decreases.

Any electrode bringing together the oxidized and reduced forms of a redox couple has what is called an electrode potential. This is achieved through the Nernst law which connects to the activity of the reactants and the products of electrochemical reaction occurring at the electrode. The ideal performance of a fuel cell is determined through the evaluation of the potential on each electrode in each fuel cell technology. In the case of the PEM cell, the previous equation becomes [9]:

$$
E=\mathrm{E}_{0}+\frac{\mathrm{RT}}{2 \mathrm{~F}} \ln \left(\frac{\mathrm{P}_{\mathrm{H} 2}}{\mathrm{P}_{\mathrm{H} 2 \mathrm{O}}}\right)+\frac{\mathrm{RT}}{4 \mathrm{~F}} \ln \left(\mathrm{P}_{\mathrm{O} 2}\right)
$$

\section{MOdELING OF CIRCUIT IMPEDANCE OF THE PEM FuEL CELL}

For a fuel cell, several models can be developed depending on the objective to be reached [4]-[7]. The integration of a fuel cell in an electrical environment requires knowledge of its electrical model.

The characterization tools were presented in the literature. We propose here to detail those which we used in our experimental tests:

- The automatic drawing of voltage-current curves.

- The impedance spectroscopy.

- The study parameters of this method depend on the richness of the information desired.

- The scanning frequency. 
- The current sweep pattern (sine, linear).

The model must be simple, precise and must predict the electrical behavior in both static and dynamic conditions.

The simplest model can be an input-output model (equivalent circuit, for example) that would allow description of fuel cell behavior in its environment.

\section{A. Characterisation and Simple Modeling of Fuel Cells}

The polarization curve of the PEM fuel cell presented in Fig. 2 is generally described as the sum of four terms: the theoretical open circuit voltage $\mathrm{E}, \mathrm{V}_{\text {act }}$ activation overvoltage, resistance overvoltage $\mathrm{V}_{\mathrm{ohm}}$ and the concentration overvoltage $\mathrm{V}_{\text {conc }}[12]$ :

$$
\mathrm{V}_{\text {fuel }}=\mathrm{E}-\mathrm{V}_{\text {act }}-\mathrm{V}_{\text {ohm }}-\mathrm{V}_{\text {conc }}
$$

Fig. 2 gives the polarization curve of the PEM fuel cell.

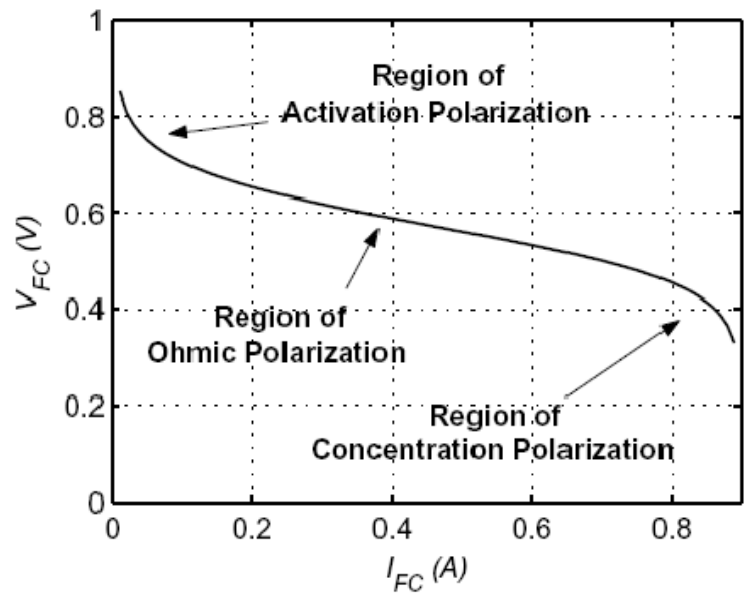

Fig. 2. Voltage-current characteristic of the fuel cells.

\section{1) Activation polarization}

The activation losses are due to starting of the chemical reactions at the anode and cathode. A portion of the available energy is used to re-form chemical bonds to the electrodes. If these losses occur at the two electrodes, the oxidation reaction of hydrogen at the anode is much faster than the reduction of oxygen at the cathode. It follows that activation losses are mainly due to cathodic reactions. The relationship between activation losses and the current density is given by equation Tafel [12]:

$$
\mathrm{V}_{\mathrm{act}}=\mathrm{A} \cdot \ln \left(\frac{\mathrm{I}_{\mathrm{FC}}+\mathrm{i}_{\mathrm{n}}}{\mathrm{i}_{0}}\right)
$$

Where $I_{F C}$ is the current delivered by the fuel cell, the exchange current $i_{0}$ characterizing empty the electrodeelectrolyte exchanges, in the internal power to take account of a possible passage of gas and / or electrons through the electrolyte and to the slope of the Tafel.

\section{2) Ohmic polarization}

The ohmic losses are due to the resistance being the electrodes and the bipolar plates to the flow of electrons and the electrolyte to the passage of protons. The corresponding voltage drop is written [12]:

$$
\mathrm{V}_{\mathrm{ohm}}=\mathrm{R}_{\mathrm{m}}\left(\mathrm{I}_{\mathrm{FC}}+\mathrm{i}_{\mathrm{n}}\right)
$$

Where $R_{m}$ is the total resistance of the fuel cell.

\section{3) Concentration polarization}

The gas consumption depletes the gas mixtures and reduces its partial pressure. This pressure reduction depends on the current issued and characteristics of gas circuits. This voltage drop is expressed in terms of a current limit $i_{L}$, for which all the fuel being used, its pressure drops to zero, and constant B called constant transport transportation or mass transfer [12]:

$$
\mathrm{V}_{\text {conc }}=-\mathrm{B} \cdot \ln \left(1-\frac{\mathrm{I}_{\mathrm{FC}}+\mathrm{i}_{\mathrm{n}}}{\mathrm{i}_{\mathrm{L}}}\right)
$$

4) Relationship Between the Polarization and the Impedance Model

In a fuel cell, several models can be developed according to the objective. The integration of a fuel cell in an electric environment requires knowledge of its electric model. The model must be simple, accurate and must allow predicting the electrical behavior both in static conditions and in dynamic regime. The simplest model can be an input-output model type (equivalent circuit, for example) which allow the description of the fuel cell behavior in its environment. The simplest representation of the fuel cell as an electric model is to put a DC voltage source in series with electrical impedance in Fig. 3.

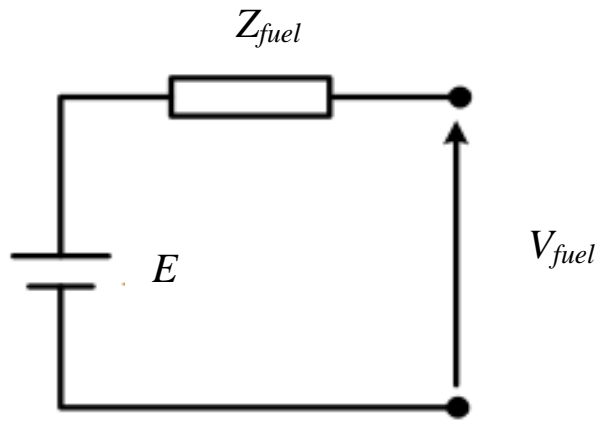

Fig. 3. Representation of a fuel cell using a voltage source associated with its electrical impedance [12].

\section{B. Impedance Model of PEM Fuel Cell}

1) Fuel cell impedance spectroscopy model

The Impedance spectroscopy is a measure conventionally used in electrochemistry. It is concerned with determining the impedance of a material or a system in response to electrical excitation.

The determination of the electrical impedance of the system is carried out in three steps [13]:

- Superposition of a sinusoidal component of small amplitude (small perturbation Signal $\delta \mathrm{I}$ ) to the direct current (or voltage) imposed on the battery for A whole range of frequencies $\left(\omega_{n}=2\right.$. $\pi . f_{n}$ the pulsation of the excitation associated with the second frequency). The DC component of the current corresponds to a point of operation on the polarization curve $V=f(I)$ of the stack.

- Measurement of the amplitude and phase shift of the sinusoidal component of the response In voltage $(\delta \mathrm{V})$ of the fuel. 
- Calculation of the complex impedance $\bar{Z}(\omega)$ (respectively the admittance) of the fuel cell over the range of frequencies studied. This impedance is defined Such as the ratio of the voltage to the current in the frequency domain; the VDC and IDC are eliminated [13].

In this section we propose an equivalent electrical circuit of the fuel cell. This circuit brings together electrical elements representing the electrical and electrochemical phenomena (loss of activation, ohmic loss, loss of concentration, double layer phenomenon) [14], [15]. These phenomena are coupled with those studied in the diffusion approach to establish the final model.

\section{2) Impedance model of randles}

In a fuel cell, several models can be developed according to the objective. The integration of a fuel cell in an electric environment requires knowledge of its electrical model. The model must be simple and should be used to predict the electrical behavior both in static mode only loaded dynamically.

The simplest model can be an input-output model type (equivalent circuit for example) that allows the description of the fuel cell behavior in its environment. The simplest representation of the fuel cell in the form of an electrical model is to a DC voltage source in series with electrical impedance (Fig. 3). The electrical impedance includes a capacitance of the double layer $C_{D C}$ and a resistance $R_{T}$ characterizing charges transport phenomena to the electrodes. The resistance $R_{M}$ represents the membrane resistance and the different others resistances in contact with the membrane in this case, diffusion phenomena are neglected.

The simplest representation of a fuel cell stack in the form of an electrical schematic diagram is given in Fig. 4. In this case, diffusion phenomena are neglected [12], [16]-[18].

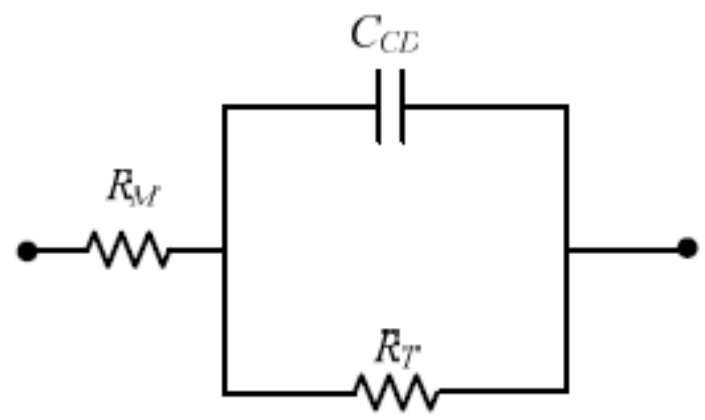

Fig. 4. Single impedance of an electrochemical cell.

So the cell impedance becomes:

$$
Z(\omega)=R_{M}+\frac{R_{T}}{\left(1+j \omega R_{T} C_{D C}\right)}
$$

And the simple model impedance scheme has the following form in the Nyquist plane as illustrated in Fig. 5.

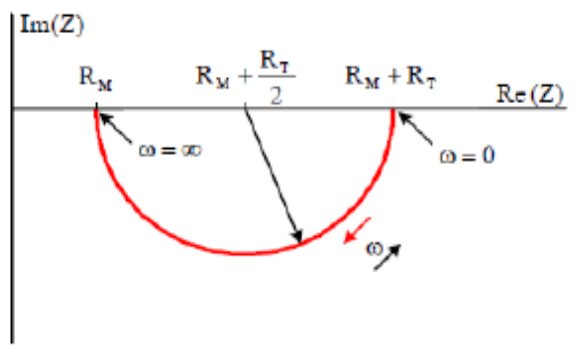

Fig. 5. Simple model impedance in the Nyquist plane.

The plot of this impedance in the Nyquist plane corresponds to a semicircle which the center is $\left(\mathrm{R}_{\mathrm{M}}+\mathrm{R}_{\mathrm{T}} / 2,0\right)$ and a radius equal to $\mathrm{R}_{\mathrm{T}} / 2$ (Fig. 3). At low frequencies, the impedance tends to $R_{M}+R_{T}$. At high frequencies; it tends to $R_{M}$.

The maximum of the capacitive effect corresponds to point $\left(\mathrm{R}_{\mathrm{M}}+\mathrm{R}_{\mathrm{T}} / 2,-\mathrm{R}_{\mathrm{T}} / 2\right)$ and is obtained for:

$$
\omega \mathrm{R}_{\mathrm{T}} \mathrm{C}_{\mathrm{DC}}=1
$$

The given experimental points represent the real and the imaginary part of the measured impedance presented in a table.

The reference impedance $\mathrm{Z}(\omega)_{\text {ref }}$ is:

$$
Z(\omega)_{\text {ref }}=\text { Real }_{\text {ref }} Z(\omega)+j . \operatorname{Img}_{\text {ref }} Z(\omega)
$$

The impedance of the selected model is a resistor in parallel with a capacitance both in series with a further resistor.

$$
Z(\omega)=R_{M}+\frac{1}{\frac{1}{R_{T}}+j \cdot \omega \cdot C_{D C}}
$$

After a mathematical calculation, the expression is divided into a real and an imaginary part

$$
\mathrm{Z}(\omega)=\mathrm{R}_{\mathrm{M}}+\frac{\mathrm{R}_{\mathrm{T}}}{1+\omega^{2} \mathrm{R}_{\mathrm{T}}{ }^{2} \mathrm{C}_{\mathrm{DC}}{ }^{2}}-\mathrm{j} \frac{\omega \mathrm{R}_{\mathrm{T}}^{2} \mathrm{C}_{\mathrm{DC}}}{1+\omega^{2} \mathrm{R}_{\mathrm{T}}{ }^{2} \mathrm{C}_{\mathrm{DC}}{ }^{2}}
$$

We set $\quad 1+\omega^{2} R_{M}^{2} C_{D C}^{2}=a$

Expression of the impedance of the model becomes:

$$
\mathrm{Z}(\omega)_{\bmod }=\mathrm{R}_{\mathrm{M}}+\frac{\mathrm{R}_{\mathrm{T}}}{\mathrm{a}}-\frac{\mathrm{j}\left(\omega \mathrm{R}_{\mathrm{T}}^{2} \mathrm{C}_{\mathrm{DC}}\right)}{\mathrm{a}}
$$

The real impedance equal model:

$$
\operatorname{Reel}_{\text {mod }}(\mathrm{Z}(\omega))=\mathrm{R}_{\mathrm{M}}+\frac{\mathrm{R}_{\mathrm{T}}}{\mathrm{a}}
$$

The imaginary impedance of the model:

$$
\operatorname{Img}_{\bmod }(\mathrm{Z}(\omega))=-\frac{\mathrm{R}_{\mathrm{T}}{ }^{2} \omega \mathrm{C}_{\mathrm{DC}}}{\mathrm{a}}
$$

\section{PARAMETERS IDENTIFICATION OF THE IMPEDANCE MODEL OF PEM FUEL CELL}

\section{A. The principle of identification method}

The principle of a method of identification is the iterative search of a set of parameters $\theta$ allowing minimizing a criterion of deviation between a model and experimental measurements, 
as illustrated in Fig. 6. The principle is to apply the same set of excitations $\mathrm{u}_{\mathrm{k}}$ to experimental measurements and to a model. The outputs $\hat{y}_{k}$ of the model and the outputs $y_{k}$ of the measurement are then compared and the set of parameters $\theta$ is adjusted to reduce the measurement-model deviation on the set of $\mathrm{N}$ iterations resulting from the applied excitation [13].

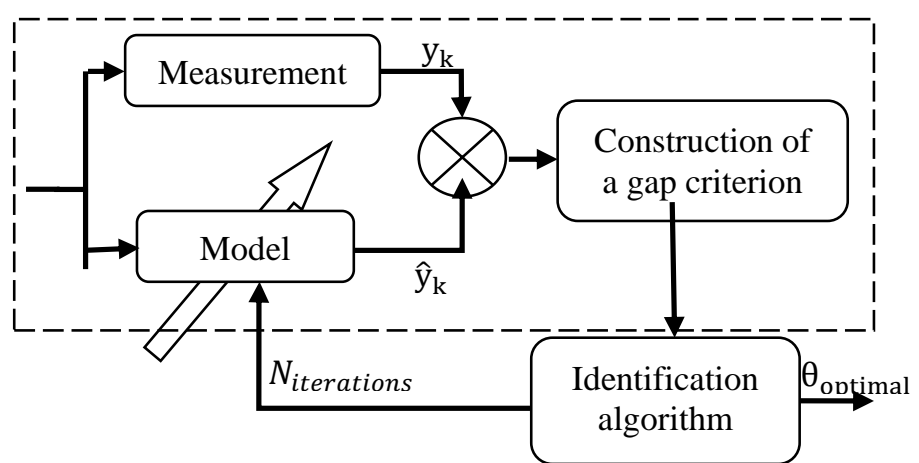

Fig. 6. Identification principle [13].

The formulation of an identification problem is reduced to the formulation of a monocriter optimization problem whose objective function is constituted by a quadratic error criterion $\mathrm{F}_{\theta}$ defined by the sum of the model-measurement errors squared. The set $\theta$ of $M$ parameters can be subject to domain constraints. In the end, the problem to solve is expressed by (17) [13].

$$
\min \left[\mathrm{F}_{\theta}\right]=\min \left[\sum_{\mathrm{k}=1}^{\mathrm{N}}\left(\hat{\mathrm{y}}_{\mathrm{k}}(\theta)-\mathrm{y}_{\mathrm{k}}\right)^{2}\right]
$$

Or $\theta=\left[\begin{array}{lll}\theta_{1} & \ldots & \theta_{M}\end{array}\right]$ With $M$ the number of parameters of the model and $\theta_{\text {i_min }} \leq \theta_{\mathrm{i}} \leq \theta_{\mathrm{i} \_ \text {max }}$ with i $\in[1 \ldots \mathrm{M}]$

\section{B. Representation of Impedance Measurements by Nyquist Diagram}

As a result of the measurements, the information can be plotted in the complex plane, the abscissa axis giving the real part of the impedance and the ordinate axis the imaginary part. This mode of representation is called a Nyquist diagram. Each point of the Nyquist diagram corresponds to the total impedance measured for a given excitation frequency during impedance spectroscopy. The Nyquist diagram is rather used by electrochemists because it facilitates the reading of phenomena with different dynamics [13]. Fig. 7 expresses the Randles model representation of the Nyquist plane.

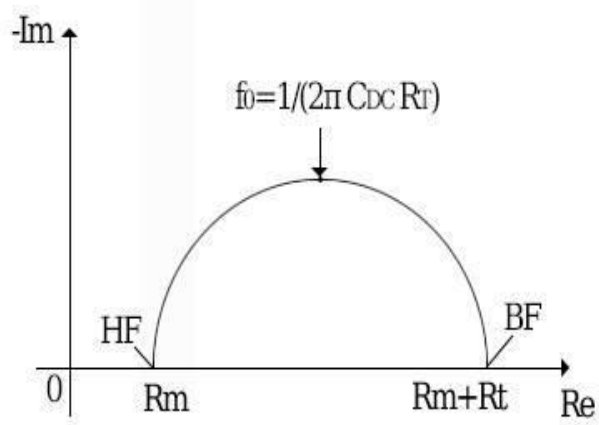

Fig. 7. Randles model representation of the Nyquist plane.
The Nyquist diagrams can provide useful information for fuel cell analysis. Thus, we usually extract the value of the real part of the intersection of the curve with the abscissa axis at the low frequencies (which corresponds to the resistance attributed to the membrane of the models presented later), the frequency at the top of the curve, and the width of the circle between the two intersections of the curve with the abscissa axis (which corresponds to the sum of the electrical resistances of the models).

\section{Methodology of Identification: Parameters Extraction}

The parametric identification of the electrochemical field differs from one researcher to another, after having obtained experimental data, they must be analyzed. For this, he chose to parameterize the models described by the researcher, so that their answers correspond to the experimental test. The set of parameters obtained will make it possible to characterize, at least in part, the state of the fuel cell at the time of the measurement. To analyze degradation, I want to compare the parameters extracted from the experimental tests carried out under degrading conditions. For impedance spectroscopy and current scans, the principle of parameter extraction is to compare the experimental reading with the result given by the model and to adjust the different parameters of the model in order to make "Paste" the Response of the latter with the Experimental. Procedure for identification by the least squares method. The objective of this section is to present the method of identifying the parameters of the impedance model using the measured values. The organizational chart of the working methodology used for the identification is given in the following Fig. 8.

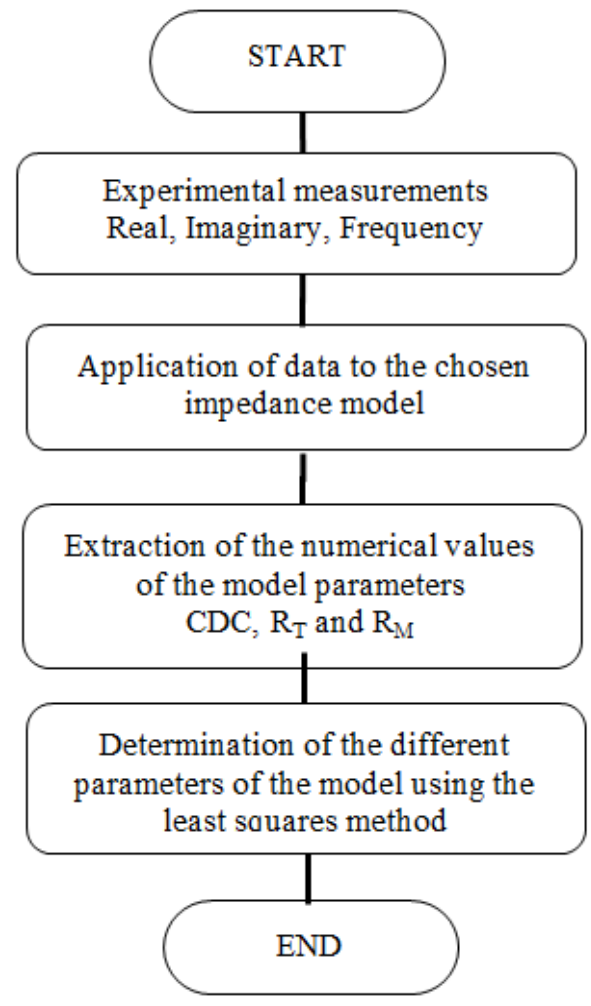

Fig. 8. Organizational chart of the methodology used for identification. 
After obtaining the reference values used in the works of Arafet and Rouane [19] and choosing the model described in Fig. 4. We can calculate and estimate the parameters of the model. The experimental points given represent the real part and the imaginary part of the measured impedance presented in a table. The reference impedance $\mathrm{Z}(\omega)_{\text {ref }}$ is:

$$
Z(\omega)_{\text {ref }}=\operatorname{Real}_{\text {ref }} Z(\omega)+j \cdot \operatorname{Img}_{\text {ref }} Z(\omega)
$$

The fuel cell impedance model is obtained by the frequency behavior of the complex impedance of the fuel cell as follows :

$$
\mathrm{Z}(\omega)_{\mathrm{ref}}=\text { Real }_{\text {model }} \mathrm{Z}(\omega)+\mathrm{j} \cdot \operatorname{Img}_{\bmod } \mathrm{Z}(\omega)
$$

Where $\operatorname{Real}_{\text {model }} Z(\omega)$ is the real of the impedance model of the fuel cell and $I m g_{m o d} Z(\omega)$ is the imaginary part of the fuel cell impedance model.

The experimental data generated by the electrochemical impedance spectroscopy method are mainly analyzed using an electric circuit model. The most of the circuit elements used in the model are the electrical elements such as resistance, capacitor, inductance and the electrochemical elements such as the Warburg impedances.

The minimization of the error between the impedance of the calculated model and the measured impedance makes it possible to find the optimal parameters minimizing the difference between each reference point and corresponding point in the model. At the start of the calculation, the initial values are assigned to these parameters. The comparison between the reference impedance and the impedance of the model is done by the error criterion or the minimization criterion of the least squares method $(\mathrm{J})$.

$$
\begin{aligned}
& J=\sum_{i=1}^{n}\left\{\left(\text { Reel }_{\text {ref }} Z_{i}-\text { Reel }_{\text {mod }} Z_{i}\right)^{2}+\left(\operatorname{Img}_{\text {ref }} Z_{i}-\right.\right. \\
& \left.\left.\operatorname{Img}_{\text {mod }} Z_{i}\right)^{2}\right\}
\end{aligned}
$$

$\mathrm{n}$ represents the number of experimental points excited by the frequency.

When the error identification criterion is validated, the resulting data set is the optimal set. The calculation stops when a stopping condition is reached, namely:

- The maximum number of iterations reached.

- The variation of tolerance of each parameter reached.

- Tolerance on the implementation error.

Before passing to the development of the proposed method, I want to remind some important points for the determination of impedance electrochemical model parameters by impedance spectroscopy. The Nyquist diagram is a set of points identified on the real part and the imaginary part measured for a frequency ranging from $0.1 \mathrm{~Hz}$ to $12 \mathrm{kHz}$.

These points from the spectrum.

So we go to the next step which is determining $\mathrm{R}_{\mathrm{M}}$. Indeed, the determination of $\mathrm{R}_{\mathrm{M}}, \mathrm{R}_{\mathrm{T}}$ and $\mathrm{C}_{\mathrm{DC}}$ depends on minimizing the error criterion $\mathrm{J}$.

\section{1) The determination of $R_{M}$}

After reading the measurements table, we obtained three vectors which the coordinates are the frequency, the real part and the imaginary part corresponding.

The high frequency HF $=[\mathrm{FHF}$ ReHF ImHF $]$

The low frequency BF $=[\mathrm{FBF}$ ReBF ImBF $]$

The average frequency MF $=$ [FMF ReMF ImMF $]$.

At the beginning of the program, $\mathrm{R}_{\mathrm{M}}, \mathrm{R}_{\mathrm{T}}$ and $\mathrm{C}_{\mathrm{DC}}$ parameters are initialized to zero. A high frequencies approximation is assumed that the imagination of the reference value is zero, we obtain the following equation:

$$
J_{R M}=\left(\operatorname{Reel}(H F)-R_{M}\right)^{2}
$$

We start the iterations and the stop condition is as follows:

$\mathrm{J}_{\mathrm{RM}} \leq \varepsilon$ Or the maximum number of iterations is attaint. So, is assigned $\varepsilon$ a value equal to $10^{-8}$ and begins to increment $R_{M}$ by a space no value $h_{1}$, whose value depends on the estimated value of the parameter to calculate. Therefore varies $R_{M}$ to have $\mathrm{J}_{\mathrm{RM}}$ exceeding $\varepsilon$ or we reached the maximum number of iterations. In this case one can say that $\mathrm{R}_{\mathrm{Mf}}$ is found.

Determining the flowchart of the $\mathrm{R}_{\mathrm{M}}$ is given in Fig. 9.

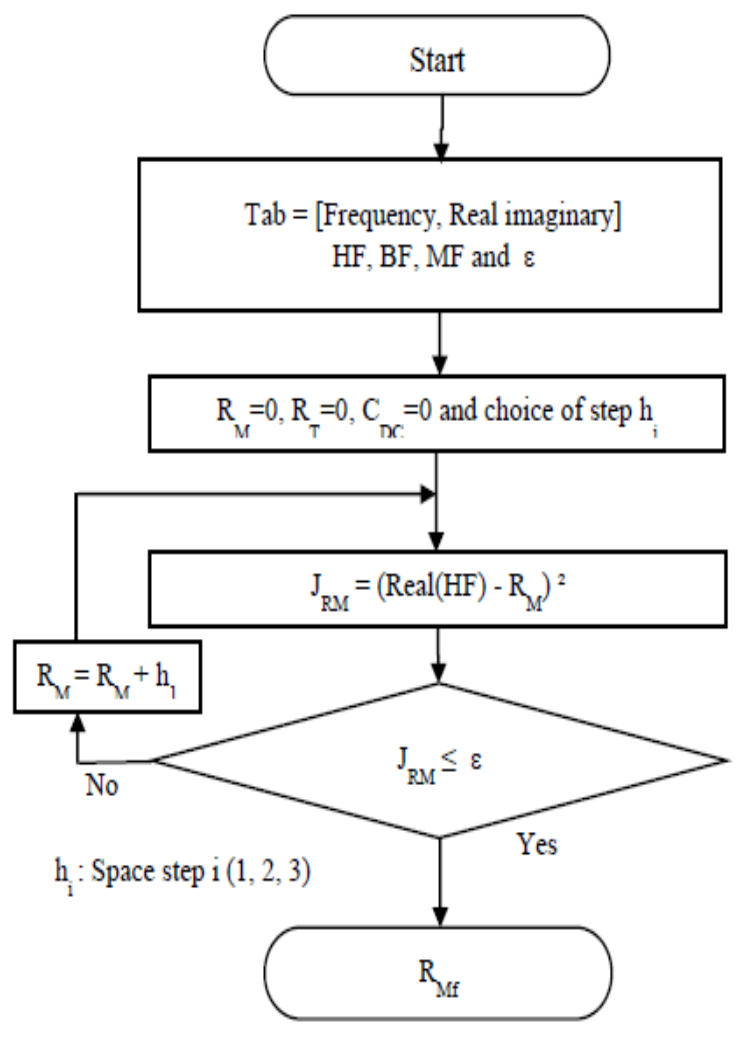

Fig. 9. Determining the flowchart of the $R_{M}$.

2) The determination of $R_{T}$

In this stage $R_{M}$ is known (computed in the previous step). At low frequencies, it is assumed that the reference imaginary is equal to zero. Therefore we obtain the following equation: 


$$
J_{R T}=\left(\operatorname{Reel}(B F)-\left(R_{M_{f}}+R_{T}\right)\right)^{2}
$$

$\mathrm{R}_{\mathrm{T}}$ is incremented by a space not $\mathrm{h} 2$ value is incremented and $\mathrm{R}_{\mathrm{T}}$ to be $\mathrm{J}_{\mathrm{RT}}$ exceeding $\varepsilon$ it reached the maximum number of iterations.

Determining the flowchart of the $\mathrm{R}_{\mathrm{T}}$ is given in Fig. 10 .

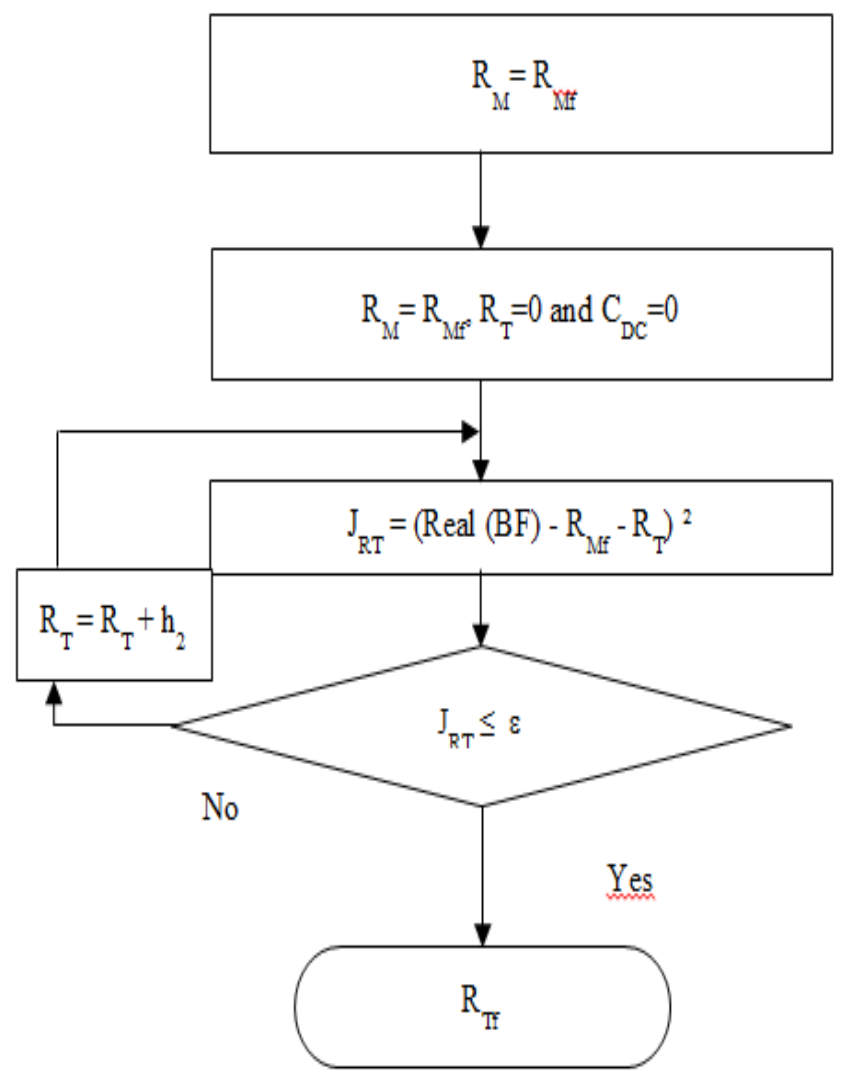

Fig. 10. Determining the flowchart of the $\mathrm{R}_{\mathrm{T}}$.

3) The determination of $C_{D C}$

The determining $\mathrm{C}_{\mathrm{DC}}$ is performed by choosing any point in the measurement chart provided that its imaginary part is not zero. An average frequency and seeks to minimize the criterion $\mathrm{J}_{\mathrm{CDC}}$ example we take while incrementing the $\mathrm{C}_{\mathrm{DC}}$ value one step $h_{3}$. The equation of the criterion to be minimized is:

$$
\begin{gathered}
J_{C D C}=\left(\operatorname{Re}(M F)-\left(R_{M f}+\frac{R_{T f}}{1+\omega^{2} R_{T f}^{2} C_{D C}^{2}}\right)\right)^{2}+(\operatorname{Im}(M F)- \\
\left.\frac{R_{T f}^{2} \omega C_{D C}}{1+\omega^{2} R_{T f}^{2} C_{D C}^{2}}\right)^{2}
\end{gathered}
$$

This step continues until the number of iterations is reached or $\mathrm{J}_{\mathrm{CDC}} \leq \varepsilon$.

Determining the flowchart of the $\mathrm{C}_{\mathrm{DC}}$ is given in Fig. 11 .

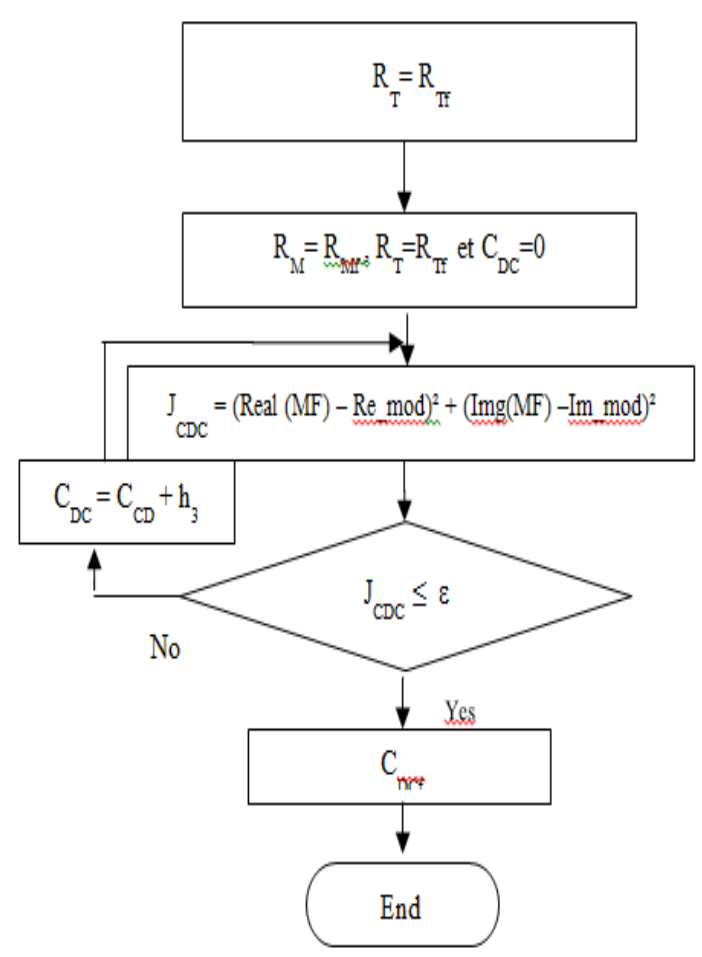

Fig. 11. Determining the flowchart of the $\mathrm{C}_{\mathrm{DC}}$.

The principle of extracting the parameters using this program is summarized by the steps indicated in Fig. 12.

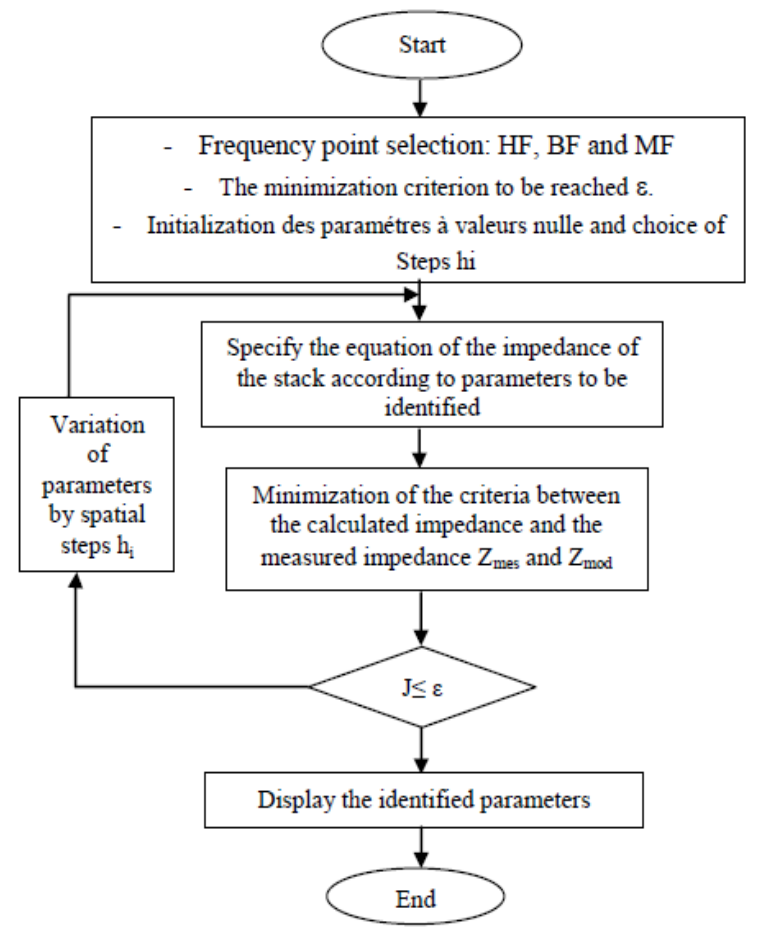

Fig. 12. Main chart calculation. 


\section{Description of the Algorithm in the Frequency Selection Program}

It is assumed that the first value in the table is the maximum frequency (high frequency).

We run the table while comparing each value to the first. It is the same routine which is repeated for the lower frequency.

For the average frequency dividing the number of rows of the table by two, the resulting value provides an indication of the value of the average frequency which will be used. Fig. 13 presents gives details about selection of frequency.

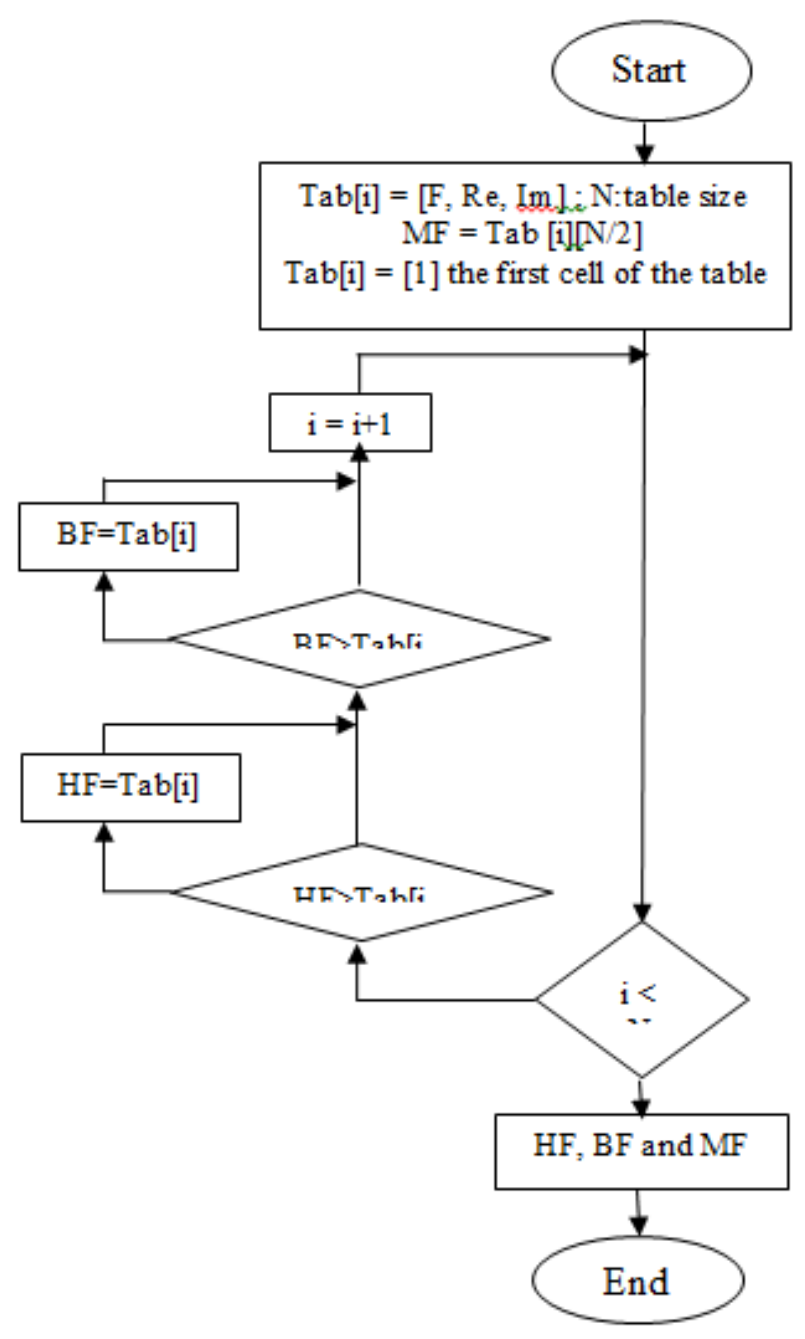

Fig. 13. Frequency selection sub-program flowchart.

\section{THE EXPERIMENTAL WORK}

The identification algorithm is developed in Matlab, software. It contains the main program, the sub-programs of the frequency selection and the parameters display. This program after simulated gives waited results as those found by Arafet and Rouane [19] for a PEMFC Nexa Fuel Cell type Ballard whose power is $1200 \mathrm{~W}$.
This validates the results found by our algorithm. Moreover, these values are almost identical to those obtained by M. Selmene et al. using the genetic algorithm [20]. These results are also close to the measured values found by Reddad [21] et al. and Rouane [22] who worked on a fuel cell having the same characteristics as the Nexa fuel cell.

The following tables show the calculating step and extract the results found during the minimization of the criterion $\mathrm{J}$ for each parameter (Tables 1, 2, and 3).

TABLE I. SOME POINT $\mathrm{R}_{\mathrm{M}}$

\begin{tabular}{|l|l|}
\hline \multicolumn{2}{|l|}{ SOME POINT CHANGES $\mathbf{R}_{\mathrm{M}}$} \\
\hline $\mathrm{R}_{\mathrm{M}}$ & $\mathrm{J}_{\mathrm{RM}}$ \\
\hline 0 & $1 \mathrm{E}-4$ \\
\hline 0.001 & $8.11 \mathrm{E}-5$ \\
\hline 0.003 & $4.9 \mathrm{E}-5$ \\
\hline 0.006 & $1.6 \mathrm{E}-5$ \\
\hline 0.00973 & $7.2 \mathrm{E}-8$ \\
\hline 0.01001 & $1.2 \mathrm{E}-10$ \\
\hline 00201 & $1.02 \mathrm{E}-4$ \\
\hline 0.031125 & $4.46 \mathrm{E}-4$ \\
\hline 0.041905 & $1.01 \mathrm{E}-3$ \\
\hline
\end{tabular}

TABLE II. SOME POINT $R_{T}$

\begin{tabular}{|l|l|l|}
\hline \multicolumn{2}{|l|}{ SOME POINT CHANGES R } \\
\hline$R_{\mathrm{M}}$ & $\mathrm{R}_{\mathrm{T}}$ & $\mathrm{J}_{\mathrm{RT}}$ \\
\hline 0.01001 & 0 & 0.0081 \\
\hline 0.01001 & 0.001 & 0.0079 \\
\hline 0.01001 & 0.003 & 0.0075 \\
\hline 0.01001 & 0.006 & 0.007 \\
\hline 0.01001 & 0.021 & 0.0047 \\
\hline 0.01001 & 0.045 & 0.002 \\
\hline 0.01001 & 0.078 & $1.44 \mathrm{E}-4$ \\
\hline 0.01001 & 0.091 & $1.0 \mathrm{E}-6$ \\
\hline 0.01001 & 0.12 & $9 \mathrm{E}-4$ \\
\hline
\end{tabular}


TABLE III. SOME POINT $\mathrm{C}_{\mathrm{DC}}$

\begin{tabular}{|l|l|l|l|}
\hline \multicolumn{5}{|l}{ SOME POINT CHANGES $\mathbf{C}_{\mathbf{D C}}$} & $\mathrm{R}_{\mathrm{TC}}$ & $\mathrm{J}_{\mathrm{CDC}}$ \\
\hline $\mathrm{R}_{\mathrm{M}}$ & 0.091 & 0 & 0.00602 \\
\hline 0.01001 & 0.091 & 0.0001 & 0.00561 \\
\hline 0.01001 & 0.091 & 0.001 & 0.00205 \\
\hline 0.01001 & 0.091 & 0.0022 & $1.67 \mathrm{E}-4$ \\
\hline 0.01001 & 0.091 & 0.0028 & $7.66 \mathrm{E}-6$ \\
\hline 0.01001 & 0.091 & 0.003001 & $6.54 \mathrm{E}-8$ \\
\hline 0.01001 & 0.091 & 0.006 & $4.8 \mathrm{E}-4$ \\
\hline 0.01001 & 0.091 & 0.01 & 0.001 \\
\hline 0.01001 & 0.091 & 0.015 & 0.0013 \\
\hline 0.01001 & & &
\end{tabular}

The convergence curves of $R_{M}, R_{T}$ and $C_{D C}$ are given in Fig. 14 to 16.

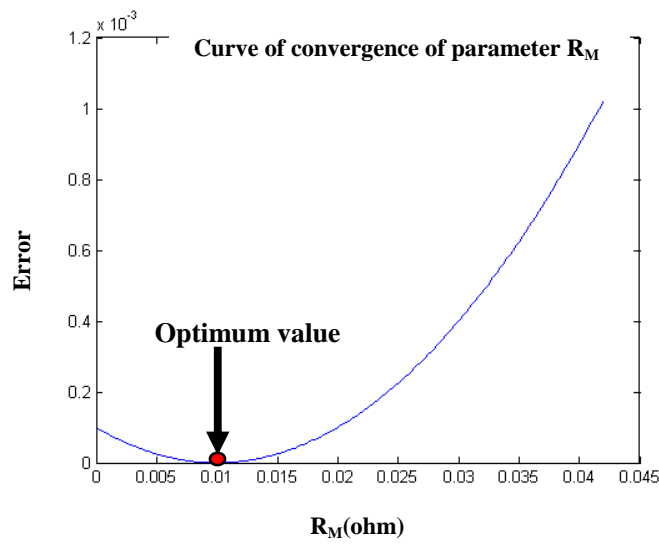

Fig. 14. Curve of convergence of parameter $R_{M}$.

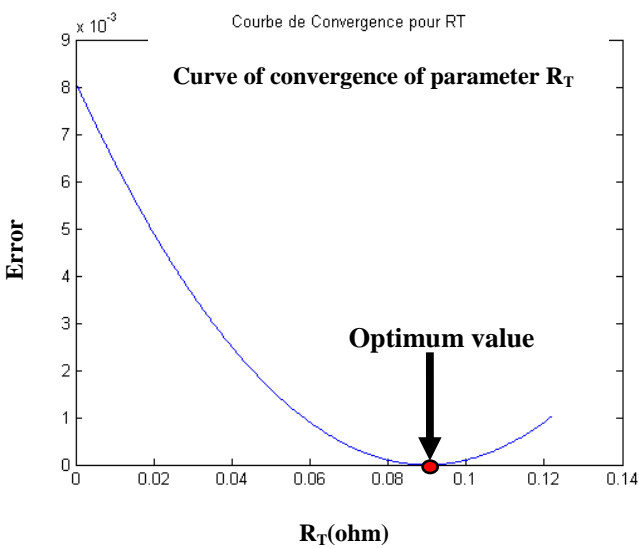

Fig. 15. Curve of convergence of parameter $R_{T}$.

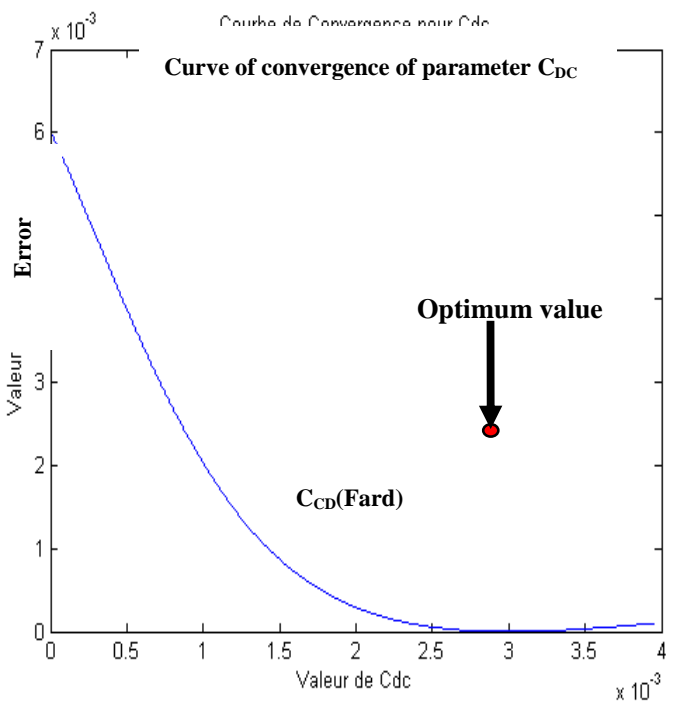

Fig. 16. Curve of convergence of parameter $C_{D C}$.

The convergence curves of different parameters admit an absolute minimum error which describes the value of each parameter so min $\mathrm{J}_{\mathrm{xx}}$ gives the exact values.

The following tables show the calculating step and extract the results found during the minimization of the criterion $\mathbf{J}$ for each parameter (Table 4).

TABLE IV. VALUES OF THE PARAMETERS IDENTIFIED

\begin{tabular}{|c|c|c|c|}
\hline \multicolumn{4}{|l|}{ Figure } \\
\hline & Fig. 10 & Fig. 11 & Fig. 12 \\
\hline Error rate $\mathrm{J}_{\mathrm{RM}}(\%)$ & $1.2 \mathrm{E}-10$ & - & - \\
\hline $\mathrm{R}_{\mathrm{M}}(\Omega)$ & 0.01001 & - & - \\
\hline Error rate $\mathrm{J}_{\mathrm{RT}}(\%)$ & & $1.0 \mathrm{E}-6$ & - \\
\hline $\mathrm{R}_{\mathrm{T}}(\Omega)$ & - & 0.091 & - \\
\hline Error rate $\mathrm{J}_{\mathrm{CDC}}(\%)$ & - & - & $6.54 \mathrm{E}-8$ \\
\hline $\mathrm{C}_{\mathrm{DC}}(\mathrm{F})$ & - & - & 0.003001 \\
\hline
\end{tabular}

The identification algorithm used is the least-squares method which makes it possible to identify the resistive and capacitive elements such as the values $R_{M}, R_{T}$ and $C_{D C}$. Model given by the table presented in Table 5 .

TABLE V. THE OPTIMAL PARAMETERS OF THE COMPLEX IMPEDANCE OF THE NEXA PEM FUEL CELL.

\begin{tabular}{|l|l|}
\hline Parameters & Numerical Value \\
\hline $\mathrm{C}_{\mathrm{DCA}}(\mathrm{F})$ & 0.003 \\
\hline $\mathrm{R}_{\mathrm{M}}(\mathrm{Ohm})$ & 0.01 \\
$\mathrm{R}_{\mathrm{TC}}(\mathrm{ohm})$ & 0.091 \\
\hline
\end{tabular}

Table 6 shows the comparison of two different method of identification and the parameters of the impedance model of a fuel cell identified in each methodology. 
TABLE VI. COMPARISON OF TWO DIFFERENT METHOD OF THE IMPEDANCE MODEL PARAMETERS IDENTIFICATION

\begin{tabular}{|l|l|}
\hline Identification methodology & Parameters to be identified \\
\hline Classical method "least square" & $\begin{array}{l}\text { Electrical parameters " } \mathrm{R}_{\mathrm{M}} \mathrm{R}_{\mathrm{T}} \mathrm{C}_{\mathrm{DC}} \text { " } \\
\text { (our case) }\end{array}$ \\
\hline $\begin{array}{l}\text { Advanced method "genetic } \\
\text { algorithm" }\end{array}$ & $\begin{array}{l}\text { Electrochemical parameters " } \mathrm{R}_{\mathrm{M}} \mathrm{R}_{\mathrm{T}} \\
\mathrm{C}_{\mathrm{DC}} \mathrm{Z}_{\mathrm{W}} \mathrm{L} \ldots \text {..." }\end{array}$ \\
\hline
\end{tabular}

The identification of the electrochemical parameters differs from one researcher to another. Philippoteau [23] choose to parameterize the models described so that the parameters obtained correspond to the experimental test. On the other hand Morin [24] was identified static and dynamic parameters to be able to simulate the dynamic model.

The objective of Morin is to determine the parameters (if included Lelec) represented on the model associated with the activation phenomena, species diffusion and charge conduction losses. Among these parameters, four (the Cdiff XXX and Cdl) concern the dynamic aspects and all the others concern the static aspect. My identification work is based on the least squared method which is closer to Philippoteau's methodology [23] at the level of parameter set obtained "criterion to minimize" will permit to characterize, at least in part, the state of the stack at the time of measurement.

But this methodology does not allow to identifying the electrochemical parameters such as the Warburg impedance and the CPE phase constant element.

In this case, we must use advanced methods like the Methaeristic technique or the network of neuron which permit to evaluate an identification work based on one of the most intelligent techniques and compares their results by what find in this paper.

\section{CONCLUSION}

In this paper, we have described a methodology for identifying the parameters of the complex impedance model of the fuel cell. This impedance model is based on electrical elements such as membrane resistance, load transfer resistance and double layer capacitor. It hangs on the mathematical equations of the elements from the experimental results by an algorithm of identification based on the method of least squares. The simulation results are presented by Nyquist diagrams to describe the different phenomena that occur inside the fuel cell.

\section{REFERENCES}

[1] H. Oman. Fuel Cells Personal Electricity. IEEE AES Systems Magazine, September 2000.

[2] 2013 Fuel Cell Technologies Market Report: Fuel Cell Technologies Office. U.S. DEPARTEMENT OF ENERGY. November 2014.

[3] Taher Hamaz, "Tools for characterization and diagnosis of a PEM fuel cell by external electromagnetic field measurement", Thesis, University Grenoble, 2015

[4] A. Forrai, H. Funato, Y. Yanagita, and Y. Kato. Fuel-Cell Parameter Estimation and Diagnostics, IEEE Transactions On Energy Conversion. Vol. 20 (3), pp. 668 - $675,2005$.

[5] K. Sugiura, M. Yamamoto, Y. Yoshitani, K. Tanimoto, A. Daigo, T. Murakami, Performance diagnostics of PEFC by current-pulse method, $\mathrm{J}$ Power Sources, (2006), Vol.157, pp. 695- 702, 2006
[6] M.A Rubio, A. Urquia, S. Dormido. Diagnosis of PEM fuel cells through current interruption, J Power Sources, 171, 670-677, 2007

[7] T. Hamaz, C. Cadet, F. Druart. Détection de dysfonctionnements d'une pile à combustible PEMFC à partir de sauts de courant. CIFA 2012, Grenoble, France, 2012

[8] A. Hernandez, D. Hissel, R. Outbib. Modeling and Fault Diagnosis of a Polymer Electrolyte Fuel Cell Using Electrical Equivalent Analysis. IEEE TRANSACTIONS ON ENERGY CONVERSION, VOL. 25, NO. 1, pp. 148- 160, 2010

[9] Marielle MARCHAND. «Water Management in Fuel Cells ». Thesis of the National Polytechnic Institute of Grenoble. Novembre 1998

[10] Benjamin BLUNIER. " Modeling motor-compressors for the air management in the fuel cell systems - simulation and experimental validation". Thesis, University of Technology Belfort-Montbéliard. December 2007

[11] Amel LACHICHI. "Modeling and stability of a hybrid current regulatorApplication to converters for fuel cells". Thesis of the University of FrancheComté. November 2005.

[12] MajidZandi. "Contribution to the management of hybrid electric power sources." Thesis of the University of the National Polytechnic Institute Lorrain. University, Nancy Novevmber 2010.

[13] Thomas GENEVE, "Methods of diagnosis of fuel cells", thesis of Institut National Polytechnique of Toulouse (INP Toulouse) February 2016

[14] Thomas Mennola, Mikko Mikkola, Matti NOPONEN, Tero Hottinen, Peter LUND, «Measurement of ohmic voltage Losses in individual cells of a PEMFC stack", Journal of Power Sources, 112: 261-272, 2002.

[15] K.R. COOPER et M. SMITH. «Electrical test methods for on-line fuel cell ohmic resistance measurement». Journal of Power Sources 160, pp. 1088-1095, 2006

[16] IdrisSadli. "Modeling impedance of a PEM fuel cell for power electronics in use".Thesis of the National Polytechnic Institute of Lorraine. December 2006.

[17] El-Hassan AGLZIM. "Characterization spectroscopy the complex impedance of impedance of a fuel cell in load Evaluation of the influence of moisture." Thesis, University Henri Poincaré-Nancy1. November 2009.

[18] Xiao-Yuan Zi . Chaojie SONG Haijiang Wang.Jiujun ZHANG. "Electrochemical Impedance Spectroscopy in PEM Fuel Cells Fundamentals and Applications".

[19] Amar Rouane, El-Hassan AGLZIM, Bernhard KRAEMER, Reddad ELMOZNINE, "Impedance Measurement of Fuel Cell is a Load". $9^{\text {th }}$ International Conference electrical power quality and use, Barcelona october 2007

[20] Mohamed Selméne Ben Yahia, Hatem Allagui, Arafet Bouaicha, Abdelkader Mami "Fuel Cell Impedance Model Parameters Optimization using a Genetic Algorithm" The International Journal of Electrical and Computer Engineering (IJECE) Vol. 7, No. 1 , February 2017, pp. 196 205

[21] El-Hassan AGAIZIM Amar rouane, Reddad EL-MOZNINE "An Electronic Measurement Instrumentation of the impedance of a Loaded Fuel Cell Battery gold.Sensors", 2007 (ISSN 1424-8220 @ 2007 by MDPI www.mdpi.org/sensors).

[22] El-Hassane AGLZIM, Amar ROUANE, Mustapha NADI and Djilali KOURTICHE, Signal Processing for the Impedance Measurement on an Electrochemical Generator, Sensors \& Transducers Journal, Vol. 90, Special Issue, pp. 150-159, April 2008.

[23] Vincent PHLIPPOTEAU. "Tools and Methods for the Diagnosis of a Health State of a Fuel Cell". Thesis of the National Polytechnic Institute of Toulouse. July 2009

[24] Benoît Morin. "Hybridisation of a fuel cell by supercapacitors to a passive and direct solution". Thesis of the National Polytechnic Institute of Toulouse. February 2013. 